\title{
"QUEM SE DIFERENCIA APANHA" (DERU KUI HA WATARERU): EXPERIÊNCIA ETNOGRÁFICA, AFETO E ANTROPOLOGIA NO JAPÃO
}

\author{
Regina Yoshie Matsue \\ Pedro Paulo Gomes Pereira
}

\section{Introdução}

Este artigo busca refletir sobre o fazer etnográfico a partir da experiência de campo com migrantes brasileiros no Japão. ${ }^{1}$ Pressupomos que a etnografia não seja somente um método, pois, além de ser uma teoria, ela implica também uma forma de ser e estar no mundo (Peirano 2014). O fazer etnográfico está presente no dia a dia do etnógrafo onde quer que se manifeste sua capacidade de estranhar. Dessa forma, é quase impossível delimitar o trabalho etnográfico e saber precisamente onde ele começa e onde termina, bem como sua extensão no tempo e no espaço. A experiência etnográfica está dentro de nós. Os fatos vividos no campo há anos, por exemplo, podem ser relembrados ou reinterpretados constantemente, com base em anedotas ou em uma nova forma de pensá-los ou concebê-los.

Neste artigo cabe uma ressalva: trata-se de um diálogo teórico-afetivo que já dura 20 anos. Nele, Regina Yoshie Matsue - aqui frequentemente denominada "a primeira autora" - realizou a pesquisa etnográfica, a concepção e a revisão do artigo. Pedro Paulo Gomes Pereira, por sua vez, participou da concepção teórica, do planejamento geral do texto, além da redação e da revisão final do artigo, o que pode ser percebido por formas verbais e pronominais características da primeira pessoa do plural. O processo aqui utilizado revela, portanto, que afecções e afetos possibilitaram a construção conjunta do texto.

A primeira autora revisitou o trabalho de campo realizado no Japão de 1998 a 2006, especialmente em algumas cidades localizadas no nordeste e noroeste da região de Kanto. ${ }^{2}$ Nesse resgate, elementos biográficos da ordem dos afetos e dos sentidos foram incorporados na interpretação etnográfica. 
Por ser nissei (filha de japoneses), sua posição no mundo foi construída a partir de um forte "vínculo" com "valores" e "ideologias" ditas japonesas. Em realidade, muitos dos nipo-brasileiros ${ }^{3}$ no Brasil (particularmente os nisseis) possuem uma "imagem idílica" do Japão como a "terra natal" (Maeyama 1984; Roth 2002; Tsuda 2006), sempre representando o homeland (Baumann 2000): "o lugar do eterno retorno" com forte apelo emocional e simbólico de ligação com a "terra dos ancestrais".

Esse "vínculo" certamente norteou seus interesses pelos estudos japoneses ainda no curso de graduação em antropologia da Universidade de Brasília, no início da década de 1990. A história da imigração e da adaptação dos japoneses em terras brasileiras a inspirava, embora a vivência doméstica a levasse a questionar muitos dos valores e das "regras de organização" e "hierarquia familiar". ${ }^{4} \mathrm{Na}$ graduação, optou por realizar uma pesquisa sobre migração, parentesco e valor da família entre duas unidades agrícolas familiares localizadas no noroeste paulista. Percebeu aí que a antropologia perpassava também as questões de ordem biográfica.

Ainda na graduação, deparou-se com textos de antropólogos japoneses, tais como Chie Nakane (1977), Harumi Befu (1985) e da antropóloga nipo-americana Dorinne Kondo. ${ }^{5}$ Os escritos destes autores a instigaram a aprofundar seus conhecimentos sobre a antropologia e a vivenciar o estudo de campo naquele país. Para tanto, dedicou-se ao estudo da língua e de textos produzidos por antropólogos e pesquisadores de áreas afins sobre o Japão. Contudo, a aspiração de estudar naquele país teve de ser adiada, pois ela imaginava que antes deveria fazer um mestrado sólido. Ingressou então no mestrado em Antropologia na Universidade de Brasília. Dessa vez, seu tema de estudo versou sobre a religiosidade dos nipo-brasileiros, especificamente sobre o budismo étnico, mantendo-se sempre vinculada às discussões sobre antropologia e religiosidade japonesas. Após concluir o mestrado, já no final da década de 1990, foi contemplada com uma bolsa de estudos que lhe permitiu concretizar a pesquisa etnográfica no Japão.

No Japão, a experiência de pesquisa a fez questionar e contextualizar os "vínculos" dos nipo-brasileiros com aquele país. Compreendeu então que a supervalorização de uma suposta "niponicidade" entre os migrantes no Brasil ainda era um reflexo do forte nacionalismo que predominou no Japão até a derrota na Segunda Guerra Mundial (Maeyama 1984). No trabalho de campo constatou que a tão vislumbrada "conexão" se torna dramática no momento em que os nipo-brasileiros se deparam com sua condição de estrangeiros no Japão. Assim, muitos que se consideram “japoneses no Brasil" tornam-se "brasileiros no Japão" (Linger 2001; Tsuda 2006). 
É nessa condição limite - ainda que porosa, ora de dentro, ora de fora - que a primeira autora constrói sua reflexão etnográfica, incluindo alguns elementos da ordem dos afetos e buscando também mostrar a preponderância de uma visão "hegemônica" oficial que domina o discurso político sobre a alteridade. Como essa noção é elaborada ou suprimida cotidianamente no discurso oficial da nação? Estas são algumas das questões que buscaremos tratar neste ensaio.

No decorrer das páginas seguintes, o leitor vai se deparar com algumas experiências vivenciadas pela primeira autora como estudante nipo-brasileira em contextos acadêmicos e em pesquisa de campo. Narramos como ela foi afetada por uma persistente interpelação de seus interlocutores para resgatar uma pretensa "niponicidade" inerente a ela. Apesar de seus esforços para se adaptar às expectativas, a sensação de inadequação se manifestava implacavelmente em seu corpo.

Na parte subsequente, exporemos elementos do trabalho de campo realizado entre os brasileiros no Japão e a maneira como a protagonista era afetada pelos problemas enfrentados pelos migrantes e suas famílias, para os quais os espaços religiosos representavam uma importante rede de apoio social. Posteriormente, destacaremos como se deu a construção e a exclusão dos "brasileiros no Japão" e, em seguida, discutiremos o ideal da constituição do discurso dominante do Estado que prega a "homogeneidade racial do povo japonês". Por fim, evocaremos os elementos de uma antropologia que inclui demandas da ordem biográfica e dos afetos. Tal antropologia buscaria uma aproximação e uma abertura em relação às teorias e às experiências vividas que possibilitam a inclusão de saberes que afetam e transformam. Do mesmo modo, indagariam hierarquias naturalizadas e assinalariam as obliterações existentes.

\section{Inadequação e incompletude}

Em outubro de 1998, a primeira autora desembarcou no aeroporto de Narita como bolsista de um programa do Ministério da Educação japonês (Monbugakkakusho) destinado a estudantes estrangeiros. Era início do outono, as folhas das árvores já começavam a trocar de cor - com variações do amarelo-claro ao ocre - e a colorir a paisagem do campus da Universidade de Tsukuba (local onde foi estudante bolsista por oito anos). Ela recorda que o ar tinha uma fragrância floral proveniente dos pequenos arbustos e flores que florescem antes do inverno. Esse ambiente mágico foi de encontro à imagem idílica que ela tinha do país, em que tudo era "belo e harmônico". 
Embora esta tenha sido sua primeira viagem ao Japão, havia um sentimento de estar "retornando" à terra natal de seus pais, o que provocou nela uma grande euforia nos primeiros meses.

Aos poucos, entretanto, ela começou a perceber que destoava da paisagem geral do Japão. A despeito de estar familiarizada com a língua, sua habilidade linguística era ainda muito limitada. O fato de ser filha de japoneses e de não ter o domínio completo da língua causava-lhe um grande constrangimento, mesmo nas coisas mais insignificantes do dia a dia. Ao ingressar na rotina acadêmica, foi alocada juntamente com todos os estudantes estrangeiros nos cursos de "japonês para estrangeiros", embora tivesse sido selecionada para compor as classes de nível avançado, juntamente com chineses e coreanos. Depois de seis meses de estudos intensivos, ela iniciou propriamente a pesquisa acadêmica que versava sobre religiosidade no Japão.

Como sua dissertação de mestrado no Brasil tinha versado sobre o budismo japonês em Brasília, ela almejava dar continuidade aos estudos sobre esta religião na Universidade de Tsukuba. Mas, para isso, era necessário ter um conhecimento mais aprofundado da língua japonesa. Seu orientador, percebendo sua dificuldade com a língua, sugeriu que ela fizesse novamente o mestrado e, paralelamente, continuasse o estudo da língua. Após passar pelo processo seletivo, ingressou no mestrado em abril de 2000. No decorrer do curso, seu interesse de pesquisa voltou-se para os grupos das novas religiões japonesas ${ }^{6}$ e suas práticas terapêuticas. Em 2002, defendeu sua dissertação, que versou sobre esta temática. Depois dessa primeira experiência, ela presumiu que já havia adquirido razoável conhecimento da língua e habilidades para lidar com as demandas da vida acadêmica e do cotidiano de uma estudante "estrangeira" no Japão. Assim, decidida a dar continuidade a seus estudos, ela se submeteu ao processo seletivo para o doutorado, que consistia em uma prova escrita, na defesa de projeto e em uma entrevista. Obtendo sucesso na primeira etapa, chegou à fase final: entrevista e defesa de projeto. Naquele dia ela seguiu o dress code para a ocasião formal: camisa branca básica, sapatos e terno pretos. Ela não sabe se por costume, distração, ou para marcar um diferencial - que inconscientemente ali se manifestava - borrifou um perfume francês sobre o seu corpo.

Ao adentrar na sala de entrevistas, constatou que a grande maioria dos professores do Programa de Pós-graduação estava presente. A maior parte era composta por homens japoneses de meia-idade, alguns professores estrangeiros e duas professoras japonesas que aparentavam ter mais de 50 anos. Enquanto a entrevista foi presidida em estilo formal pelo chefe de 
departamento, a arguição do projeto coube ao seu futuro orientador. Alguns professores fizeram perguntas adicionais, mas as duas professoras japonesas permaneceram caladas e sérias.

O resultado foi divulgado oficialmente uma semana depois: para sua felicidade, ela havia sido aprovada. Contente, foi à sala de seu orientador para fazer-lhe a comunicação oficial. Entretanto, ao recebê-la, o professor relatou seu "profundo constrangimento" pelo fato de ela ter usado perfume na ocasião e pela repercussão dessa conduta sobre sua imagem como pesquisadora. Segundo ele, as professoras japonesas argumentaram que uma mulher que usa perfume não seria uma pesquisadora séria, uma vez que isto denotava um caráter fútil. E, diante disso, elas poderiam recusá-la como aluna do programa de doutorado.

Essa revelação deixou-a petrificada. Um misto de vergonha e constrangimento tomou conta de seu ser. O professor continuou a falar, assinalando que entendia o seu deslize por ela ter sido educada na "cultura latino-americana". E foi somente por esta razão que ele havia pedido que "as feministas lhe dessem a chance e a aceitassem como aluna". Seu orientador era um professor sênior e pelo fato de ser homem e de ocupar uma posição superior à das professoras, ${ }^{7}$ elas não tiveram outra opção a não ser a de a admitirem como aluna do programa de doutorado. Entretanto, seu professor a advertiu para que nunca mais usasse perfume em ambiente acadêmico e fosse discreta em termos de vestimentas, adornos e gestos.

Esse evento foi emblemático para sua posição limítrofe, como filha de migrantes japoneses e como mulher, o que a levou a uma constante autovigilância em relação às suas ações e ao seu corpo. A partir de então, ela tentou mudar seus hábitos corriqueiros e até mesmo seu tom de voz, perfazendo uma busca inalcançável de não destoar no meio dos outros alunos e de não ser alvo de críticas. Afinal, como não cansavam de lembrar, Deru kui ha utareru. Tal ditado popular (cotowaza) quer dizer literalmente "prego com a cabeça saliente é martelado", ou "quem se diferencia é criticado". Durante oito anos ela viveu situações que a faziam recordar tal experiência. As correções cotidianas e as frases de desaprovação iam construindo em seu corpo novas posturas e desenvolvendo outras maneiras de falar. Conforme John Austin (1990), as palavras fazem, a ação é realizada por meio do dizer.

Convém ressaltar que este fato ocorreu em uma das universidades que mais recebem alunos estrangeiros no Japão. Em um departamento em que quase 50\% dos(as) alunos(as) eram estrangeiros(as) das mais variadas nacionalidades. Tal episódio pontuou múltiplos aspectos da sua socialização como aluna nipo-brasileira. Por ser filha de japoneses, havia uma expectativa maior sobre seu comportamento do que sobre o de seus colegas estrangeiros 
não descendentes. Obrigatoriamente, seus interlocutores exigiam dela ações consideradas como "adequadas". Para eles, como já havia apontado Dorinne Kondo (1986), ela deveria ter incorporado tais "formas adequadas de comportamento" na educação fornecida no seio de sua família.

De acordo com as teorias sobre a niponicidade (nihonjinron), "ser japonês" é definido por três critérios: raça/sangue, cultura/língua e território (Befu 2001). ${ }^{8}$ Com base nessa concepção, ser racialmente japonesa implicava também dominar a língua e comportar-se de determinada maneira. Assim, suas ações "inadequadas" e seus erros linguísticos provocavam reações de perplexidade e de repulsa. Essa sensação foi semelhante à vivenciada por Glória Anzaldúa (1987): também de incompletude e inadequação. No entanto, ao contrário dela, por apresentar traços fenotípicos que a igualavam ao povo local, os que a circundavam se obrigavam a bater na cabeça do prego até ele se moldar.

Parecia haver um tácito acordo por parte de seus colegas, professores e de outras pessoas com os quais convivia para que ela se comportasse como um deles. Nas universidades japonesas, em geral, os alunos de pós-graduação se mantêm afiliados ao grupo de pesquisa do professor orientador. Nos seminários semanais, os pesquisadores se reúnem em uma sala de pesquisa onde todos têm seu espaço para trabalhar diariamente e discutir questões da investigação. Nessas ocasiões, suas tentativas para fazer uma boa apresentação individual e provocar discussões eram sempre frustradas, uma vez que seus colegas evitavam discutir ou confrontar ideias. Era como se existisse uma regra velada, implícita de não enfrentamento; as questões que geravam polêmica ou discórdia eram evitadas ou ignoradas. ${ }^{9}$

Nesses momentos de exposição pública, ela percebia também uma constante vigilância sobre suas ações. A postura corporal e a tendência de gesticular com as mãos enquanto apresentava eram alvo de críticas, razão pela qual seus colegas teciam comentários, tais como: "É mesmo uma latina..." (Ratten dakara... ou Yappari ratten da né...). Com isso, ela foi aprendendo que era necessário trabalhar seu corpo a partir do olhar do outro. A inadequação não era só linguística, mas também corporal e, assim como se esforçara para aprender o japonês, ela deveria se empenhar em transformar seu corpo, suas técnicas corporais. Infelizmente, as leituras sobre técnicas corporais de Marcel Mauss (1984) não a haviam alertado para todas as dificuldades de aprender a lidar com o corpo segundo a expectativa do outro.

Com o tempo ela foi criando um vínculo com os colegas de classe e com os estudantes do grupo de estudos de seu orientador. No horário do almoço, os alunos se reuniam para comer juntos e, periodicamente, havia os nomikais (happy hours), momentos de descontração dos quais os professores também 
participavam. Nessas ocasiões, o mais importante era compartilhar, beber e comer juntos. Os Izakayas (tipo sofisticado de petiscaria e bar) são famosos por servir iguarias nacionais. Se comparadas ao paladar brasileiro, tais iguarias seriam consideradas "exóticas", tais como finos de filés de cavalo servidos crus (basashi) ou salada de soja fermentada (natto). O fato de a primeira autora apreciar pratos típicos da culinária japonesa era motivo de deleite para seus colegas, uma demonstração de sua "niponicidade". Nesses encontros, seus colegas e professores davam-lhe não só dicas valiosas sobre sua pesquisa, mas também informações sutis de como não destoar, para que ela pudesse adequar suas posturas corporais. Por exemplo, seus colegas enfatizavam a importância de ela participar ativamente dessas confraternizações, uma vez que isso mostrava seu esforço em aprender com eles, ao contrário da maioria dos estrangeiros que preferia ficar fora das atividades do grupo de estudo. Sua participação deixava claro que ela tinha um "espírito japonês" (nihonjin no kokoro).

Aprendeu também que uma das regras de etiqueta para começar uma conversação com o orientador, em meio a um nomikai, era estar atenta para oferecer-lhe bebida, não deixando que seu copo se esvaziasse, até que outro(a) aluno(a) passasse a servi-lo. Percebeu que aqueles eram alguns dos raros momentos em que se podia ter uma conversação informal e estreitar relações com os professores e colegas em torno da mesa de um Izakaya. Desse modo, numerosas vezes seguiu tal prática à risca. Com todo o seu esforço, seus erros linguísticos e deslizes de comportamento eram tolerados. Por exemplo, a linguagem utilizada em uma conversação com um professor deve ser a de respeito, utilizando termos honoríficos (keigo), na qual os pronomes e a flexão verbal são diferentes dos da linguagem coloquial. Porém, em meio a um nomikai, isso era muito difícil de ser seguido e ela sempre cometia algumas falhas. Ao falar "professor (sensei), veja isso", ela muitas vezes dizia: "sensei, kore wo mitekudasai", porém a forma adequada de respeito de dizer a mesma coisa deveria ser "sensei, kore wo goran ni natte kudasai". Seus colegas a alertavam, mas, às vezes, eram indulgentes: "Você se esforça bastante" (Kimi ha yoku gambatteiru né). Esse reconhecimento, entretanto, exigia que ela fosse receptiva às críticas de seus interlocutores e mostrasse empenho para aprender. Havia assim um grande esforço de sua parte em se adequar para ser aceita.

Essa tendência em ressaltar em si uma pretensa "niponicidade" se manifestava também fora do ambiente acadêmico, em exercícios mais lúdicos. Para ter uma maior interação com os locais, ela buscava afazeres fora da universidade, como a prática da cerimônia do chá e da caligrafia, atividades que cultivou por mais de seis anos. Recorda que sua instrutora, diante do 
seu esforço, dizia: "Você tem espírito de japonês" (Matsue-san ha nihonjin no kokoro wo motteimasu). Quando visitava seu tio paterno que não havia migrado, ele aconselhava: "Você retornou às suas origens, de agora em diante deveria ficar no Japão definitivamente" (Kimi ha Nihon ni modotta, korekara zutto nihon ni itte). Parecia que todos, inclusive ela mesma, conspiravam para que ela assumisse "um modo de ser japonês". Para este fim, ela esperava que o controle diário e o esforço sistemático pudessem lentamente moldar suas ações e seu corpo.

A constante vigilância sobre as ações demonstrava como o corpo está imerso em um campo político, sendo invariavelmente sujeito a técnicas cotidianas e a manipulações, de acordo com Marcel Mauss (1984) e Michel Foucault (1987). Durante os oito anos em que estudou no Japão, ela teve de lidar diariamente com essa sensação de incompletude e, ao longo desse tempo, desenvolveu um tipo de maleabilidade necessária para viver em traduções, tal qual aponta Anzaldúa (1987). Ela devia aprender a atuar e a movimentar-se de acordo com a expectativa dos que a circundavam, só assim o corpo poderia tornar-se não somente útil e eficiente, mas também dócil. É neste ponto que o poder disciplinador se revela bem sucedido.

O exercício de tal poder oferece interpretações, pois somos convencidos a melhorar nossas ações e a moldar nosso corpo na medida em que desejamos ser aceitos e incluídos. Tais mecanismos, ao mesmo tempo, controlam e produzem o corpo. E, no caso da primeira autora deste texto, eram uma porta para estabelecer certa comunicação. As relações cotidianas capturaram-na e incansavelmente iam inserindo mecanismos que atuavam sobre seu corpo e suas ações. Contudo, ao deixar-se afetar, experimentou também as disjunções e os desconfortos desse domínio. A partir da afetação ela pôde vislumbrar formas de resistências.

E foi assim que a experiência etnográfica permitiu que ela não só se afastasse da noção de "niponicidade" presente no discurso oficial do Estado, como também fizesse parte de seu imaginário. Ela admite assim que a afinidade e o afeto envolvidos na pesquisa etnográfica configuram uma análise em espiral, com curvas planas que giram em torno dessa temática, ora se afastando, ora se aproximando.

A seguir, narraremos alguns aspectos da sua pesquisa de campo e de como, inevitavelmente, ela foi sendo afetada pelas vivências entre os brasileiros no Japão. Expomos elementos do trabalho de campo realizado entre os brasileiros no Japão e a maneira como a primeira autora era afetada pelos problemas enfrentados pelos migrantes e suas famílias, para os quais os espaços religiosos representavam uma importante rede de apoio social. 


\section{A experiência etnográfica: os brasileiros no Japão (Burajirujin no basho)}

Em um primeiro momento, seu projeto de pesquisa de doutorado visava investigar as práticas mágico-religiosas de grupos religiosos considerados "folclóricos do Japão". Baseada em trabalhos seminais, tais como o do folclorista Yanagita Kunio ${ }^{10}$ e o do historiador da religião Ichiro Hori, ${ }^{11}$ planejava fazer, primeiramente, um vasto estudo bibliográfico sobre o assunto para depois se aprofundar no budismo místico. Naquele tempo, ela acreditava que este tema poderia proporcionar-lhe continuidade e aprofundamento de sua pesquisa na área de antropologia da religião. Entretanto, em suas visitas constantes às localidades onde residiam os brasileiros e em função do contato com suas problemáticas sociais, afetou-a um novo tipo de interpelação, sobre a qual falaremos adiante. Somando-se a isso, sua experiência como estudante nipo-brasileira que vivia a mesma situação de liminaridade incentivava-a a trabalhar entre os brasileiros. Consciente e inconscientemente, ela queria investigar como a construção de alteridade agia e manifestava-se nos corpos dos migrantes.

Aos poucos ela redirecionou os eixos da sua pesquisa etnográfica no doutorado para as questões que afligiam os brasileiros no Japão. Percebeu que os grupos religiosos representavam o lugar por excelência de socialização dos migrantes, o local onde se reuniam para celebrar, comer, confraternizar, construindo desse modo uma rede de apoio ou formas elementares de cidadania (Turner 2011). Seu projeto de doutorado versou então sobre religiosidade e apoio social entre os migrantes brasileiros, com seu trabalho de campo abrangendo várias localidades espalhadas pela região de Kanto ${ }^{12}$ (província de Tóquio e de outras províncias vizinhas).

Paralelamente à sua pesquisa de campo, ela engajou-se durante quatro anos como tradutora da prefeitura e como professora auxiliar em uma escola primária que recebia grande quantidade de alunos brasileiros. Tais atividades a impeliam a buscar um diálogo que permitisse o reconhecimento das diferenças e, sobretudo, apontasse a permeabilidade nelas existente. Assim, ela buscava realizar o trânsito no qual todos nós reconstruímos a nós mesmos a partir da imagem que nossos interlocutores nos devolviam (Silva 2015). Ao pesquisar sobre a questão dos decasséguis, ${ }^{13}$ ela percebeu que tal situação era coletiva, com algumas nuances individuais. Vivenciavam realidades semelhantes, mas o fato de ela ser estudante colocava-a em uma situação privilegiada. Assim, aprendeu a lidar com seus dilemas cotidianos, reportando-se às possibilidades de "reconstrução do self", na relação dinâ- 
mica com seus interlocutores, driblando, portanto, uma possível "dissolução do self", como descrito por Kondo (1986) em sua experiência de trabalho de campo no Japão.

A pesquisa de campo no Japão ocorreu de abril de 2003 a março de 2006, sendo retomada de janeiro a abril de 2008, e incluiu visitas periódicas a cidades com grande concentração de brasileiros. Cabe ressaltar que atualmente cerca de 215 mil brasileiros vivem e trabalham no Japão. Em Hamamatsu (província de Shizuoka) e Oizumi (Gunma), chegavam a constituir cerca de 10\% da população local. Nas províncias de Saitama e de Gunma foram realizadas visitas constantes às cidades de Kumagaya, Ota e Oizumi. Em Tochigi e Ibaraki, as cidades de Moka, Mitsukaido, Tsuchiura e Ishige tinham ruas ou espaços com facilidades para os brasileiros. Desde o início do processo migratório, eles organizaram-se entre si em busca de formas alternativas de socialização ou serviços (lojas de produtos brasileiros, supermercados, restaurantes, agências de turismo, salões de beleza, igrejas, bancos etc.). Por um lado, tais facilidades simplificavam a vida dos migrantes, mas, por outro, restringiam as formas de sociabilidade. ${ }^{14}$

Nessa condição de exclusão social em que viviam os brasileiros, os grupos religiosos representavam então um local privilegiado de socialização e network entre os compatriotas. Além de oferecerem serviços religiosos, suporte moral para a manutenção de valores e de identidade cultural, orientavam também na educação dos filhos e nas ações de prevenção contra conflitos pessoais, familiares e sociais. Grosso modo, a afiliação religiosa ajudava a mobilizar recursos humanos e institucionais em prol do reconhecimento de valores culturais e religiosos alternativos, favorecendo um empoderamento do migrante (Matsue 2012, 2013; Matsue \& Ogasavara 2013).

Na pesquisa de campo, a primeira autora deste texto realizou também a observação participante das atividades e das celebrações de três grupos religiosos, entre eles os católicos e os dois grupos das novas religiões japonesas (a Igreja Messiânica e o neobudismo da Soka Gakkai) que atuavam entre os brasileiros. Nessa região havia cerca de 12 igrejas católicas, quatro centros de Johrei da Igreja Messiânica e cinco grupos da Soka Gakkai que atendiam basicamente aos brasileiros. ${ }^{15}$

Adiante discutiremos como a ideologia política dominante do Estado que prega a "homogeneidade racial do povo japonês" propiciou a entrada dos nipo-brasileiros no Japão, ao mesmo tempo em que os excluiu por serem "diferentes". Destacaremos então como se deu a construção e a exclusão dos "brasileiros no Japão". 
Há uma ligação, mas... (En ga aru kedo...):

o tênue vínculo dos nipo-brasileiros com o Japão

Até hoje o Estado japonês mantém uma política restritiva à entrada de trabalhadores estrangeiros. Entretanto, os descendentes nipônicos são aceitos pelo fato de pertencerem a uma linhagem familiar japonesa, ainda que seja um vínculo distante. No discurso oficial do governo japonês há uma alusão aos laços de consanguinidade e pertencimento dos filhos e netos de japoneses nascidos no exterior. Desse modo, a entrada desses trabalhadores representou uma forma de aliviar o problema da carência de mão de obra, ao mesmo tempo em que se buscava manter a ideologia da homogeneidade racial.

Os nipo-brasileiros são racialmente japoneses, mas "falharam" por serem culturalmente brasileiros e por não possuírem o domínio do idioma e da cultura japonesa como se esperava. Assim sendo, muitos descendentes nipônicos que se consideravam "japoneses no Brasil" são discriminados como "brasileiros no Japão", caracterizando-se como uma diáspora dual (Linger 2001; Tsuda 2006). Segundo Stuart Hall (2005), o processo de construção e reprodução da identidade da diáspora deve ser percebido como algo em constante transformação, variando de acordo com as circunstâncias histórico-culturais em que o grupo está inserido. A identidade é então uma "celebração móvel", transformada continuamente em relação às formas pelas quais somos representados ou interpelados nos sistemas culturais que nos rodeiam.

Os brasileiros são identificados pela forma de se comportar, andar, vestir e gesticular. A primeira autora recorda a primeira vez em que passou pela cidade de Oizumi, local de grande concentração de brasileiros. No carro, com seu tio (japonês) que morava perto dessa cidade, percorreram uma rua onde estava localizado o Plaza Shopping, com restaurantes e várias outras lojas direcionadas à clientela brasileira. Ao observar o local, ela teve a estranha sensação de estar em alguma cidade no interior do Brasil, mas os comentários de seu tio a fizeram lembrar que estava no Japão. Talvez ele quisesse mostrar-lhe tal espetáculo ao apontar os transeuntes, indicando como eles eram visivelmente brasileiros (burajirujin). A forma de se vestir, de mover-se e de gesticular denunciava a brasilidade. As mulheres vestiam calças e blusas justas, moldando as curvas do corpo, que são imperceptíveis nas mulheres japonesas; os homens trajavam bermudas e camisetas largas que permitiam ver tatuagens nos braços, que simbolizam a marginalidade. Tudo isso criava uma imagem que destoava dos demais habitantes locais. 
Em suas várias atividades no Japão, a primeira autora deste texto destaca que muitas vezes serviu de tradutora para acompanhar estrangeiros em hospitais. Eram trabalhadores que viviam nos arredores, mas não falavam japonês. Relata que certa vez auxiliou um rapaz brasileiro, de no máximo 30 anos, que se queixava de fortes dores no braço após levar um tombo de bicicleta quando se dirigia ao trabalho. Por sorte, ele possuía um vínculo empregatício formal e estava assegurado pelo sistema nacional de saúde. No pré-atendimento do pronto-socorro, tudo aconteceu normalmente, sendo então encaminhado à consulta. O médico fez algumas perguntas e pediu-lhe que tirasse a camisa para poder examiná-lo melhor. O tronco desnudo deixou à vista uma enorme tatuagem nas costas, o que levou o médico a dizer: "Isso não é bom" (Sore ha amari yoku nai).

Em outras ocasiões, nas entrevistas com as mulheres brasileiras, sempre havia queixas sobre o comportamento insolente (sukebe) por parte dos homens japoneses nos locais de trabalho. Tocavam-nas geralmente nas nádegas ou em outras partes do corpo. E, quando elas se queixavam, os superiores argumentavam que o fato de as mulheres brasileiras usarem roupas apertadas, expondo o corpo, gerava este tipo de comportamento em alguns homens japoneses.

Esses exemplos mostram que o "brasileiro" era identificado a partir da própria corporeidade. Cria-se um modo de relacionar-se com os brasileiros por meio da desvalorização de sua alteridade. Eles eram constantemente vigiados, uma vez que suas ações e seus corpos não eram domesticados ou submissos às normas locais. Como representavam uma ameaça, eram assim excluídos e categorizados como estrangeiros (gainjin). Novamente, as diferenças se tornavam visíveis aos olhos dos locais; os corpos eram estigmatizados, tornando-se símbolos da alteridade.

Nesse cenário de marginalização, mesmo que a maioria dos migrantes brasileiros seja oriunda da classe média - independentemente da posição social ou profissão exercida no Brasil - no Japão eles se tornam invariavelmente trabalhadores braçais, operários da linha de produção de automóveis, peças, eletroeletrônicos, alimentos, produtos químicos. Desempenham trabalhos totalmente impessoais, mecânicos e repetitivos, sendo estigmatizados por três palavras começadas pela letra "k": kiken (perigoso), kitsui (árduo) kitanai (sujo). Esse trabalho é desprezado pelos trabalhadores japoneses, porém realizado por cidadãos de segunda categoria e/ou migrantes.

Os brasileiros são contratados por meio das grandes empreiteiras que terceirizam seu trabalho para pequenas empresas fornecedoras de peças às grandes indústrias. Consequentemente, eles são operários temporários, sem os mesmos status e direitos (estabilidade, pensão, seguro-desemprego e de 
saúde e possibilidade de ascensão no emprego) concedidos aos trabalhadores locais. Isto isenta o empregador das responsabilidades sociais para com os migrantes, tornando-os mão de obra descartável e barata. Diante dessa realidade, muitos dos trabalhadores brasileiros e suas famílias vivem um processo de migração circular entre o Brasil e o Japão, em que a readaptação em ambos os países é difícil (Yamanaka 2003). Alguns, há quase 30 anos residindo no Japão, dispõem apenas do visto temporário ou de permanência. Nos últimos anos, a tendência dos brasileiros de permanecer no território japonês vem trazendo implicações em relação ao status socioeconômico e político e ao futuro desses migrantes e seus filhos. Nesse cenário de exclusão e marginalização, questões de cidadania, saúde, educação e participação social e política se tornam prementes.

Ao longo dos quatro anos em que a primeira autora trabalhou em uma escola primária na cidade de Ishige como tradutora e mediadora entre os alunos brasileiros, seus pais, a coordenação e os professores da escola, ela percebeu que essa lógica de exclusão poderia ser reproduzida na geração dos filhos. Por se tratar de uma típica escola japonesa, as crianças brasileiras tinham muita dificuldade com o aprendizado da língua e, consequentemente, das disciplinas que compunham o currículo escolar. Além disso, como havia muitas regras que os alunos e seus pais brasileiros desconheciam, muitas escolas contratavam pessoas bilíngues na tentativa de adaptá-los à vida escolar.

As crianças brasileiras eram desencorajadas a falar português, pois deviam aderir às regras locais. O uso do brinco pelas meninas era coibido nas escolas, sendo motivo de discórdias entre pais e professores e de bullying por terem "um buraco na orelha" (mimi ni ana ga aiteiru!). Muitas vezes a primeira autora aconselhou os pais a abolir o uso dos brincos para não causar problemas na escola. Contudo, havia mães brasileiras que resistiam alegando que o brinco tinha um valor sentimental para ambas, mãe e filha, pois era um presente de batismo: "Não posso abdicar do presente que a minha mãe deu para minha filha, é parte da minha filha. Se eu tirar dela, é como se eu tirasse um pedaço dela". Em muitos casos, a negociação entre os pais e os servidores da escola era bastante tensa. Portanto, era a partir do corpo que as discriminações ocorriam; o uso de determinadas roupas e adereços, as formas de comportamento, as posturas, a tonalidade da voz e até mesmo a ortografia eram motivo de discriminação entre crianças e professores.

O Japão carece de uma política de educação que considere a alteridade, razão pela qual os alunos estrangeiros sofrem uma forte pressão para se ajustarem às normas das escolas japonesas (Nukaga 2003; Riordan 2005). Tendo em vista esse estado de desvalorização da alteridade, muitas 
crianças brasileiras começaram a rejeitar os próprios pais, envergonhados da precária adaptação destes e de sua falta de domínio da língua. Com isso, como apontou Lask (2000), várias crianças se recusavam a sair com seus pais na rua e a falar o português em casa. Consequentemente, grande parte das crianças brasileiras não desenvolvia fluência na língua portuguesa, mas também não conseguiam uma completa alfabetização na língua japonesa, razão pela qual não alcançavam o mesmo rendimento escolar que os alunos japoneses. Assim, muitos jovens abandonavam a escola após concluir o ensino médio; alguns ingressavam no mercado de trabalho prematuramente, de tal modo que a segunda geração de brasileiros, alguns nascidos no Japão, tem perpetuado o legado dos seus antecessores. Diante desse panorama, eles não terão diploma escolar e serão condenados a trabalhos não qualificados tanto no Brasil quanto no Japão. Com poucas chances de mudar seu status na sociedade, eles se enquadrarão permanentemente na classe de cidadãos de segunda categoria (Green 2010).

Nos últimos anos, a situação dos trabalhadores brasileiros se tornou ainda mais precária. Em fevereiro de 2009, como resultado da crise econômica mundial de 2008, 15\% dos brasileiros que viviam no Japão estavam sob a ameaça de perder o emprego ou de ter seus salários reduzidos (Shishito \& Souza 2016). Em 2011, a catástrofe ambiental - um terremoto seguido por um tsunami e por um acidente nuclear na região nordeste - abalou a economia do país. Locais distantes das áreas mais atingidas também sofreram as consequências da crise; os trabalhadores temporários não conseguiram a renovação de seus contratos, e o setor de lazer passou por uma diminuição drástica no movimento habitual. A falta de componentes nas fábricas atrapalhou a cadeia produtiva nacional, fazendo com que operasse com capacidade reduzida.

A seguir, analisaremos as condições que levaram à construção das alteridades no Japão, com base em situações históricas e políticas.

\section{A alteridade negada}

Temos insistido no fato de que a situação dos nipo-brasileiros está relacionada à forma como o Japão lida com os outros. A questão da supressão da diferença sempre esteve presente no imaginário da construção do país. O contato com outros povos aconteceu desde os primórdios da formação da história japonesa e se intensificou a partir do expansionismo territorial e militar. As condições históricas e políticas da construção das alteridades foram submetidas a um regime imperialista posto em prática desde o 
período Tokugawa com a anexação dos territórios de Hokkaido, ao norte, e de Okinawa, ao sul, que tinham populações nativas com línguas e culturas completamente diferentes das do continente. No início do século XX, as atividades expansionistas do Estado japonês culminaram com a anexação de algumas regiões da China, tais como o território da Manchúria, Taiwan e Nanquim, e com a ocupação da Coreia, que por 35 anos (1910-1945) foi colônia do império.

No entanto, até hoje o ideal do desenvolvimento da nação se baseia no mito da "homogeneidade racial do povo japonês". Existe uma vasta literatura denominada nihonjinron, que alimenta a fábula sobre as "especificidades do povo japonês" e do Japão. A premissa básica é a de que os japoneses são um "povo homogêneo" (tan'intsu minzoku) que constitui uma "nação racialmente unificada" (tan'intsu minzoku kokka), cuja "essência cultural" é a mesma desde os primórdios até atualmente. A "sociedade japonesa" é "singular e única, inigualável a nenhuma outra, tendo a orientação grupal como moldadora do comportamento". Embora o termo nihonjinron seja uma abreviação conveniente, os escritos enquadrados nessa categoria abrangem temas como o "ethos do bushido", a estética, a "ética do trabalho e da poupança" como parte do "caráter do povo", entre outros. Assim, a nihonjinron carece de unidade ou coerência interna para se qualificar como um sistema unificado de conhecimento, fazendo parte do imaginário do povo e da nação (Alves Pereira 2014; Burgess 2014).

Todo esse "saber", juntamente com suas práticas discursivas, compõe um potente dispositivo, que está implícito também nos discursos oficiais do Estado. O que está em jogo é a luta pelo controle da narrativa histórica: são tentativas de o dominador silenciar ou de apagar a versão do subalterno (Carvalho 2001). Contudo, há estudos e evidências históricas que questionam tal noção dominante da homogeneidade (Weiner \& Hanami 1998; Komai 2001; Weiner 2004). Estes autores argumentam que o arquipélago japonês sempre foi o lar de diversas populações, a despeito de uma narrativa hegemônica da uniformidade racial e cultural que exclui a existência de minorias étnicas e ignora suas contribuições culturais.

Grosso modo, há seis grupos minoritários no país citados pelos pesquisadores japoneses e estrangeiros: os burakumin, os ainu, os okinawanos, os chineses, os coreanos e os imigrantes (denominados newcomers). Até a década de 1980, os governantes e a elite política do país negavam a existência desses grupos minoritários, refletindo uma costumeira idealização do passado e uma supressão de fatos históricos e sociais (Burgess 2014; Alves Pereira 2014). 
Com base em tais evidências, muitos estudiosos assinalaram como as condições históricas e políticas de grupos submetidos a um regime colonial definiram a forma como se deu a construção da alteridade no Japão. Os fatos históricos apontam o discurso da homogeneidade racial como uma narrativa persistente de intelectuais e da elite japonesa que excluía a contribuição dos povos colonizados e conquistados na época da expansão imperialista japonesa (Befu 2001; Lie 2001; Weiner 2004). Essas narrativas assumem um papel central na autopercepção que os japoneses têm (Ryang 2004; Burgess 2014). Como vimos, tais dispositivos (discursos e práticas) foram sendo produzidos historicamente, mas atuaram sobre corpos e almas, exorcizando os perigos para dominar seus acontecimentos aleatórios. Nessa trama histórica, não houve espaço para a alteridade. Todos os corpos que por algum motivo não se submeteram à norma foram excluídos e/ou discriminados.

Os burakumin, por exemplo, não são discriminados por serem de uma etnia diferente, mas pelo fato de pertencerem à base da estratificação social, estabelecida no período Tokugawa (1600-1867). Eles faziam parte da categoria marginalizada que trabalhava em profissões consideradas abjetas: a lida com corpos e cadáveres humanos ou de animais. Apesar de no século $\mathrm{XX}$ as medidas e as leis terem buscado introduzir melhorias para esse grupo minoritário, ainda existe um tipo de discriminação velada que impede a incorporação e a ascensão social do grupo como um todo. Estima-se a existência de 2 a 3 milhões de descendentes dos burakumin que parecem invisíveis ao observador comum, sendo porém identificados pelo local de origem e pelo nome de família (Amos 2014). Atualmente, além dos grupos citados anteriormente, há também outras minorias discriminadas oficialmente pelo Estado, tais como as vítimas das bombas atômicas (hibakusha), as minorias sexuais, outros grupos de migrantes ilegais (tailandeses, indonésios, iranianos etc.) e refugiados que vivem no Japão.

Na próxima parte evocaremos os elementos de uma antropologia que inclui demandas da ordem biográfica e dos afetos. Tal antropologia busca uma abertura às teorias e às experiências vividas que possibilitam a inclusão de saberes que afetam e transformam. Do mesmo modo, indaga hierarquias naturalizadas e assinala as obliterações existentes.

\section{Elementos de uma teoria vivida}

Após o longo período de imersão no campo, a primeira autora teve necessidade também de distanciamento espacial e temporal para perceber que todas as experiências vividas faziam parte da sua etnografia, sem 
momento certo para começar e acabar. Sendo arbitrários, tais momentos reverberam no tempo e no espaço. Cabe salientar que os "fatos etnográficos" se constituem de eventos que vemos, ouvimos e interpretamos de um ponto de vista analítico. A memória etnográfica é revivida a partir da potencialidade de uma experiência, da necessidade de reexaminar eventos, vividos ou observados, que por alguma razão nos marcaram. E assim nos tornamos agentes na nossa etnografia.

Há um movimento contemporâneo que incita o questionamento da noção convencional da etnografia como método, enfatizando a capacidade do estranhamento como ferramenta fundamental da antropologia. Nesta perspectiva, as teorias são corporificadas, ou seja, as experiências pessoais e corporais do pesquisador estão no centro do fazer etnográfico. No caso desta pesquisa, a experiência corpórea na vida cotidiana também foi importante. Percebemos que a participação da primeira autora não foi somente um adjetivo para a sua observação, mas definiu também aquilo que surgia como etnografia. O campo, portanto, não está lá; ele está dentro de nós (Peirano 2008). Essa interioridade do campo é crucial para a reflexão etnográfica. Não se trata de uma interioridade apenas intelectual ou dos conceitos, mas das afecções e dos afetos: ela manifesta-se no corpo. Referimo-nos, assim, a uma antropologia mais aberta às experiências corpóreas do antropólogo no campo. Paul Stoller (1997), em sua etnografia entre os Songhay, observou como a vida cotidiana desse povo se dava de acordo com metáforas gustativas, apontando também que há culturas que se movem em torno de símbolos observáveis e sensoriais.

Em alguns momentos, entre seus interlocutores, a primeira autora não sabia bem se já era etnógrafa, pois ser afetada supõe que se assuma o risco de ver seu projeto de conhecimento se desfazer ao conceder estatuto epistemológico a situações de comunicação involuntárias e não intencionais às quais ela se submetia. No momento em que ela estava sendo afetada, ela não conseguia perceber como as experiências eram corporificadas. $\mathrm{O}$ distanciamento espaço-temporal lhe facultou notar que, ao ser afetada pelo campo, a experiência etnográfica se transformou em um dispositivo que lhe permitiu (re)elaborar um saber. Ao experimentar o campo e as relações em que estava inserida, ela se expôs a ele. O fato de aceitar ocupar o lugar de sujeição e de ser afetada por ele abriu uma comunicação específica com seus interlocutores: uma comunicação sempre involuntária e desprovida de intencionalidade, verbal ou não, mas corporificada. Favret-Saada (2005) já havia apontado a importância do afeto no fazer etnográfico, uma vez que a eficácia terapêutica da etnografia se dá quando se trabalha o afeto não representado. 
Todavia, percebemos hoje que, voltando a essas experiências corpóreas vividas e cheias de significados, reconstruímos nossa etnografia. Na verdade, segundo Tim Ingold (2010), a mente não é um órgão inerte, misturando-se despudoradamente com o corpo e com o mundo no conduto das operações. Portanto, as memórias, as narrações e as representações não são objetos, mas sim ações corporificadas no mundo.

Nesse processo, o retorno ao Brasil e o diálogo com a antropologia aqui formulada fizeram com que a primeira autora percebesse que até então estava presa a um tipo de fazer etnográfico centrado em metáforas visuais e distanciado das questões do afeto. Além disso, a antropologia japonesa, em geral, segue um modelo de pesquisa etnográfica focalizado em outras sociedades de países da Ásia, da Oceania e da África (Yamashita 2004). Portanto, as pesquisas que objetivam questões enfrentadas pela própria sociedade japonesa contemporânea são escassas entre os antropólogos japoneses; geralmente, aquelas de cunho crítico sobre o contexto interno são realizadas por pesquisadores estrangeiros (Lie 2001; Linger 2001; Ryang 2004; 2005; Tsuda 2006) ou por antropólogos japoneses radicados fora do Japão (Befu 2001). Consequentemente, esta pesquisa de campo causava certo estranhamento entre os colegas e os professores nativos da primeira autora, já que novamente ela estava sendo intrometida ao apontar os problemas nevrálgicos relacionados aos migrantes e à questão da alteridade tão polêmica entre eles.

Assim, a volta ao Brasil e a reflexão sobre a experiência vivida revelaram outros aspectos de sua etnografia, que não só era engajada, mas também terapêutica. O sentido da experiência etnográfica da primeira autora deixou de ser pessoal para ser interpretada a partir das circunstâncias em que ela ocorreu, implicando também a posição do autor: quem estuda? O quê? Sobre quem? A definição explícita da situação do autor no jogo geopolítico pôde reconstruir e avaliar o exercício etnográfico (Carvalho 2001). Neste ponto, o caminho buscava uma antropologia dos afetos que pudesse ir além da reificação e do poder (Pereira 2014). Se relações sujeitassem as pessoas aos mecanismos de controle e coerção, os afetos poderiam revelar hesitações e lapsos. Em vez de focalizar aquilo que era reificado pelo Estado-nação, a antropologia dos afetos permitia mostrar as realidades dos corpos abjetos que resistiam aos encontros complexos e à exclusão, com seus limites e traduções.

Ao realizar seus estudos de campo, sua condição de mulher e filha de migrantes lhe impôs um silêncio sobre as questões que a afligiam. Lá, a construção da alteridade, geralmente, era feita por meio do preconceito que negava ou desvalorizava a identidade do outro. Em um primeiro momento, esse mecanismo social neutralizava o poder de resistência que o outro 
pudesse oferecer. Tal como os trabalhadores brasileiros e suas crianças, ela se sentia desvalorizada e fragilizada entre seus interlocutores, não oferecendo muita resistência às interpelações que surgiam. Todavia, a busca de contextualização e da compreensão dos mecanismos que criaram essa autoidentificação negativa expôs lapsos e disjunções de tal reificação.

Com base nessa contextualização e na inclusão dos afetos, ela pôde apontar os elementos de dominação que são aceitos como naturais. Assim, o lugar - de dentro e de fora - do ser híbrido era um meio privilegiado de reflexão. Era nesse espaço que o sujeito subalterno encontrava a dimensão terapêutica, apropriando-se da palavra argumentativa e do texto cultural com maior criatividade e força de persuasão.

Parafraseando Veena Das (2007), aqui a experiência vivida e o sentido do cotidiano não se pautam nos prejuízos causados, mas na criatividade da vida que liga o presente com o passado. O passado encontra o presente não como uma memória danosa, mas como um "conhecimento venenoso". ${ }^{16}$ A profundidade temporal em que a subjetividade se constrói revela como podemos utilizar os signos do prejuízo e dar-lhes novo significado. Assim, os fatos rotineiros vividos entre os brasileiros no Japão fazem parte agora de um mosaico interpretativo sobre sua condição subalterna na perspectiva hegemônica do Estado-nação. É então na cotidianidade dos fatos descritos que se encontram os elementos perceptíveis da sujeição - bem como da resistência - como as duas faces de uma mesma moeda. O desconforto e a incompletude permitem à alteridade uma maleabilidade: uma necessidade de viver em traduções que buscam contextualizar e transformar um conhecimento dito "venenoso".

\section{Considerações finais}

Com base em um relato que mesclava a experiência vivida e a do campo do etnógrafo, buscamos nos subtítulos anteriores refletir sobre a inadequação e a incompletude dos brasileiros em vários contextos no Japão. Tal teoria crítica necessitou ser afetada pela experiência e pelo corpo. Em um primeiro momento, identificamos a ação do mecanismo do discurso dominante na vida cotidiana. Afinal, através do corpo fomos afetados, postos em movimento de registro, de aprendizagem e de criação.

Destacamos neste texto como a questão da alteridade foi apontada a partir das diferenças expressas no corpo dos sujeitos subalternos. A condição de subalternidade limitava a agência dos migrantes brasileiros, ou de outros grupos minoritários no país, de lutar contra a autoidentificação negativa que 
lhes era infligida pela sociedade. Contudo, tais diferenças representavam também uma forma de resistência, de desafio às convenções sociais e de abertura de novas formas de viver. Tal análise permitiu-nos, assim, não só indagar as hierarquias dominantes e naturalizadas pela ideologia hegemônica do Estado, mas também evidenciar os silêncios e as obliterações vividos pela alteridade.

Ademais, as afecções conduziram-nos a uma interpretação etnográfica livre de esquemas teóricos explicativos, mas atenta ao que está muitas vezes implícito e é reprimido pelo pesquisador em sua análise. Tal reflexão representou uma tentativa existencial e intelectual de retratar a pesquisa de campo, apontando a complexidade dos desafios em dialogar com a teoria antropológica, em trazer achados etnográficos genuínos e-quem sabe? - em alargar as possibilidades de se pensar a etnografia. E, para isso, recorremos à centralidade e à insistência na questão do afeto, que dá o tom criativo e visceral dessa teoria na qual a personalidade do pesquisador, suas experiências vividas, os diálogos e o contexto em que ela acontece estão presentes na análise etnográfica. O afeto representa, portanto, as forças que nos levam a ultrapassar a distinção entre sujeitos e objetos, pois, quando somos afetados, passamos a ser igualmente sujeitos e objetos.

Recebido em 09 de janeiro de 2017

Aprovado em 15 de julho de 2017

Regina Yoshie Matsue é professora colaboradora do Programa de Pós-

Graduação em Saúde/Unochapecó, Chapecó, SC, Brasil.

E-mail: <rymantsue08@yahoo.com>

Pedro Paulo Gomes Pereira é professor associado da Universidade Federal de

São Paulo, São Paulo, SP, Brasil. E-mail: < pedropaulopereira@gmail.com> 


\section{Notas}

1 Talvez pela inércia constitutiva da linguagem, ora e vez surge no artigo termos como Japão, japoneses, cultura japonesa, até por estarmos de alguma forma abordando a antropologia realizada no Japão. Por exemplo, a noção de Japão como Estado-nação. Tal conceito foi criado a partir da Revolução Meiji, sendo naturalizado e reificado pelos estudos sobre esse país somente a partir da Segunda Guerra Mundial. Desde então surgiram outros conceitos derivados, tais como niponicidade, self, raça e cultura japonesa, dentre outros (ver Ryang 2004).

2 Região populosa de 43 milhões de pessoas situadas em torno de Tóquio. Inclui também as províncias de Kanagawa, Chiba, Saitama, Ibaraki, Tochigi e Gunma. A pesquisa de campo, contudo, se deu com maior intensidade nas cidades de Tsukuba, Joso e Mitsukaido (província de Ibaraki), Kumagaya e Ota (província de Saitama), Oizumi (província de Gunma) e na cidade de Moka (Tochigi). Tais cidades contavam com a presença massiva de brasileiros, razão pela qual alguns autores as caracterizavam como "Little Brazils" (Roth 2002; Tsuda 2006).

3 Alguns estudos contemporâneos trabalham com a ideia de "japonesidades múltiplas". A escolha do termo no plural reflete uma estratégia de reflexão sobre os fenômenos étnicos que representam formas alternativas e heterogêneas de pensar a "identidade nipodescendente" (Machado 2011).

4 A maioria dos estudos sobre a "organização familiar japonesa" aponta que as relações são estruturadas a partir de regras hierárquicas verticais baseadas em gênero e na senioridade (Nakane 1977; Befu 1985). Entretanto, alguns autores contemporâneos, baseados em dados etnográficos, criticam a reificação de um "modelo invariável de família japonesa", apontando as diversificações regionais de "formas de organização familiar" e que também sofreram transformações ao longo do tempo (ver Ryang 2004).

5 A antropóloga Dorinne Kondo, filha da diáspora japonesa nos Estados Unidos, realizou pesquisas etnográficas sobre o self e a cerimônia do chá. Além disso, escreveu um texto que versa sobre sua dramática experiência de desintegração do self na realização de seu trabalho de campo. De certa forma, os dilemas apontados por Kondo em seus textos instigam a conhecer e a experienciar o trabalho de campo no Japão (Kondo 1985, 1986).

6 Embora não exista consenso sobre o assunto, os novos movimentos religiosos são aqueles que surgiram no final do período Tokugawa (1868) e no início do período Meiji (1868-1912), ganhando força e influência depois da Segunda Guerra Mundial, quando foi instalada a liberdade de culto. O termo "novo" indica que houve um movimento espontâneo de surgimento de novas seitas em contraste com as grandes tradições do xintoísmo e do budismo. Os estudiosos costumam associar as características dessas novas formas de religião a alterações profundas na ordem política, econômica e social do Japão. As novas religiões japonesas possuem, em sua maioria, uma natureza sincrética e centram-se na pessoa e no ensinamento pretensa- 
mente singular de um fundador, proveniente do povo. A essas características deve-se acrescentar a orientação das novas religiões para este mundo a partir de práticas e rituais mágicos e a visão milenarista, ou seja, a crença de que o paraíso terrestre será vivenciado pelos fiéis (Paiva 2005; Matsue \& Ogasavara 2013).

7 Apesar da revisão da Lei de Oportunidades Iguais de Emprego, de 1999, as desigualdades no trabalho e a disparidade entre os salários de homens e mulheres no Japão é a maior dentre todos os países considerados desenvolvidos. Esta prática é justificada pela ideologia de Estado, vigente desde o período Meiji, que enaltece o papel produtor e provedor do homem na família. Este deve ter dedicação exclusiva à empresa, enquanto à mulher cabe o papel de reprodutora e "dona de casa profissional", boa administradora dos afazeres domésticos e também tutora no desempenho das crianças na escola. O lema do Estado é o de que as mulheres devem ser boas esposas e mães educadoras (ryosai kenbo), ou seja, a dedicação deve ser exclusiva à família e à educação dos filhos. As poucas mulheres que investiram em suas carreiras e permaneceram competitivas no mercado de trabalho, com raras exceções, toleram tais desigualdades (Hirao 2001; Shuto 2009; Sekiguchi 2010).

8 Esta definição do "ser japonês" é baseada nas teorias do nihonjinron que, em distintos momentos históricos, debateram acerca das "particularidades tipicamente japonesas" ou "genuinamente" de uma "tradição japonesa". Tais teorias surgiram a partir de várias obras literárias ou acadêmicas que construíram aquilo que seria a "integridade identitária" do povo japonês. Essa identidade, associada à homogeneização racial e cultural, enaltecia o nacionalismo (Sasaki 2009; Alves Pereira 2014).

9 Vários estudos difundem a imagem do self japonês como interdependente. Grosso modo, tais estudos apontam que a pessoa deve buscar encaixar-se e ajustar-se às relações sociais de acordo com as expectativas do grupo em que está inserido, de tal modo que não haja ênfase nas atividades ou nos feitos realizados individualmente, mas sim no esforço em adequar-se (Kitayama et al. 1997). Vale lembrar, contudo, que alguns pesquisadores contemporâneos criticam essa visão reificada do self, apontando a influência da ideologia, do discurso político dominante e das interações cotidianas na construção do self (Ryang 2004).

10 Yanagita Kunio (1875-1962) foi responsável, no final da década de 1920, pelo desenvolvimento de um estilo de antropologia original, cujo enfoque estava centrado nos estudos sobre o folclore japonês, diferentemente dos outros escritores da época que recebiam grande influência da antropologia europeia.

11 Hori Ichiro (1910-1974) foi um destacado historiador das religiões na Universidade de Tóquio.

12 O país é um arquipélago de várias ilhas, cujas quatro maiores são Honshu, Hokkaido, Kyushu e Shikoku, representando em conjunto 97\% da área terrestre nacional. Contudo, a Ilha de Honshu é a maior e a mais importante no cenário político e econômico; nela se localizam as maiores cidades japonesas com seus polos industriais, incluindo: Tóquio, Yokohama, Osaka, Nagoia, Kobe, Kyoto, Hiroshima, dentre outras. A região metropolitana de Tóquio (que inclui a capital e várias prefei- 
turas adjacentes) é a maior área metropolitana do mundo, com mais de 30 milhões de habitantes. Ressalta-se que $82 \%$ da população japonesa residem na ilha de Honshu, que representa $61 \%$ do território. Honshu é dividida por regiões, como: Tohoku (Nordeste), Chubu (Centro), Kanto (Leste), Kansai ou Kinki (Centro-Oeste) e Chugoku (Oeste) (Oficial Statistics of Japan, 2015).

13 O termo foi usado originalmente para designar os imigrantes japoneses das regiões menos industrializadas no nordeste da ilha de Honshu e de outras regiões que foram trabalhar nas regiões industrializadas do Japão. Desde os meados da década de 1980, o termo passou a ser usado para denominar os nikkeis, ou seja, pessoas descendentes de japoneses oriundos de diferentes países que vão trabalhar temporariamente no Japão (Beltrão \& Sugahara 2006).

14 Muitos autores apontam para a formação de "Little Brazils" no Japão, devido à visível aglomeração das facilidades e das moradias dos brasileiros se concentrarem em determinados espaços de várias cidades espalhadas pelas regiões de Kanto (Tóquio e as províncias circunvizinhas) e Chubu (especialmente as províncias de Shizuoka e Aichi) (Lask 2000; Roth 2002; Tsuda 2006). Tais comunidades, no entanto, não representam enclaves fechados, e sim espaços com limites porosos, de circulação e de negociação entre os interesses diferenciados entre os próprios brasileiros e seus filhos e entre os brasileiros e os locais (Lask 2000).

15 No período de março de 2003 a junho de 2006, foram realizadas aproximadamente 20 entrevistas com sacerdotes, padres, irmãs e líderes religiosos, e mais de 30 entrevistas-narrativas de histórias de vidas com brasileiros que eram membros assíduos de um dos grupos religiosos. As entrevistas versavam sobre as dificuldades enfrentadas pelos brasileiros no Japão e o papel dos grupos religiosos em suas vidas.

16 A antropóloga Veena Das (2007) utiliza a metáfora de "conhecimento venenoso" para falar como as mulheres atuam sobre o sofrimento a elas infringido. Ao dialogar com mulheres que sofreram violência sexual durante o processo de partição do Paquistão da Índia, Das revela que elas utilizavam a metáfora de uma mulher que bebia veneno e o mantinha dentro de si. Surgiam ali figuras de linguagem para escapar de narrar diretamente os atos violentos. Esse conhecimento manifestava-se no cotidiano e nas formas de perceber a vida, permitindo-lhes operar as experiências de sofrimento no cotidiano e na reconstrução do dia a dia (Das 2007; Pereira 2010). 


\section{Referências bibliográficas}

ALVES PEREIRA, Ronan. 2014. "O discurso da homogeneidade racial, as minorias sociais e a internacionalização do Japão à luz do Caso Kajiyama". In: Ronan A. Pereira \& Tae Suzuki (orgs.), O Japão no caleidoscópio: estudos da sociedade e da história japonesa. Campinas: Pontes. pp. 145-174.

AMOS, Timothy D. 2014. Embodying difference: the making of Burakumin in modern Japan. Honolulu: University of Hawai Press.

ANZALDÚA, Gloria. 1987. Bordelands/la frontera: the new mestiza. San Francisco: Spinsters/Aunt Lute.

AUSTIN, John Langshaw. 1990. Quando dizer é fazer. Porto Alegre: Artes Médicas.

BAUMANN, Martin. 2000. "Diaspora: genealogies of semantics and transnational comparison". Numen, 47:313-337.

BEFU, Harumi. 1985. Japan: an anthropological introduction. New York: Charles E. Tuttle Company.

. 2001. Hegemony of homogeneity: an anthropological analysis of Nihonjinron. Melbourne: Trans Pacific.

BELTRÃO, Kaizô Iwakami; SUGAHARA, Sonoe. 2006. "Permanente temporário: decasséguis brasileiros no Japão". Revista Brasileira de Estudos de População, 1:61-85.

BURGESS, Chris. 2014. "Japão multicultural? O discurso e o mito da homogeneidade reexaminados". In: Ronan A. Pereira \& Tae Suzuki (orgs.), O Japão no caleidoscópio: estudos da sociedade e da história japonesa. Campinas: Pontes. pp. 109-144.

CARVALHO, José Jorge de. 2001. "O olhar etnográfico e a voz subalterna". Horizontes Antropológicos, 7(15):107147.
DAS, Veena. 2007. Life and words: violence and the descent into the ordinary. Berkeley: University of California Press.

FAVRET-SAADA, Jeanne. 2005. "Ser afetado". Cadernos de Campo, 11:155-161.

FOUCAULT, Michel. 1987. Vigiar e punir. Petrópolis: Vozes.

GREEN, Paul. 2010. "Generation, family and migration: young Brazilian factory workers in Japan". Ethnography, 11(4):515-532.

HALL, Stuart. 2005. "Cultural identity and diaspora". In: J. Rutherford (ed.), Identity: community, culture and difference. London: Lawrence \& Wishart. pp. 222-237.

HIRAO, Keiko. 2001. "Mothers as the best teachers: Japanese motherhood and early childhood education". In: M. Brinton (ed.), Women's working lives in East Asia. Stanford: Stanford University. pp. 180-203.

INGOLD, Tim. 2010. "Da transição de representações à educação da atenção". Educação, 33(1):6-25.

KITAYAMA, Shinobu; MATSUMOTO, Hisaya; MARKUS, Hazel Rose \& NORASAKKUNKIT, Vinai. 1997. "Individual and collective processes in the construction of the self: self-enhancement in the United States and self-criticism in Japan". Journal of Personality and Social Psychology, 72(6): 1245-1267.

KOMAI, Hiroshi. 2001. Foreign migrants in contemporary Japan. Melbourne: Trans Pacific Press.

KONDO, Dorinne. 1986. "Dissolution and reconstitution of self: implications for anthropological epistemology". Cultural Anthropology, 1(1):74-88. 
. 1985. "The way of tea: a symbolic analysis". Man, 20(2):287-306.

LASK, Tomke. 2000. "Imigração brasileira no Japão: o mito da volta e a preservação da identidade". Horizontes. Antropológicos, 6(14):71-92.

LIE, John. 2001. Multiethnic Japan. Cambridge: Harvard University Press.

LINGER, Daniel. 2001. No one home. Stanford: Stanford University Press.

MACHADO, Igor José. 2011. Japonesidades multiplicadas: novos estudos sobre a presença japonesa no Brasil. São Carlos: EdUfscar.

MAEYAMA, Takashi. 1984. "Burajiru Nikkeijin ni Okeru Esunishiti to Aidentiti (the ethnicity and identity of the Nikkeijin in Brazil)". Minzokugaku Kenkyu, 48(4):444-458.

MATSUE, Regina Yoshie. 2012. "Sentir-se em casa longe de casa: vulnerabilidade, religiosidade e apoio social entre os migrantes brasileiros no Japão". Ciência e Saúde Coletiva, 17(5):1135-1142.

. 2013. "Religiosidade e rede de apoio social na vida das mulheres brasileiras e suas famílias no Japão". Saúde e Sociedade, 22(2):298-309. .; OGASAVARA, Mário Henrique. 2013. "A eficácia simbólica e terapêutica de práticas religiosas entre os trabalhadores brasileiros no Japão". Religião e Sociedade, 33(2):102-120.

MAUSS, Marcel. 1984. "As técnicas corporais". In: Sociologia e antropologia. São Paulo: EPU/Edusp. pp. 211-233.

NAKANE, Chie. 1977. Japanese society. Harmondsworth: Penguin Books.

NUKAGA, Misako. 2003. "Japanese education in an era of internationalization: a case study of an emerging multicultural coexistence model". International Journal of Japanese Sociology, 12(1):79-94.

OFICIAL STATISTICS OF JAPAN. 2015. "Portal site of oficial statistic of Japan". Disponível em: www.e-stat. go.jp. Acesso em abril de 2017.

PAIVA, Geraldo José. 2005. "Novas religiões japonesas e sua inserção no Brasil: discussões a partir da psicologia". Revista USP, 67:208-217.

PEIRANO, Mariza. 2008. "Etnografia, ou a teoria vivida". Ponto Urbe, 2:2-9. 2014. "Etnografia não é método". Horizontes Antropológicos, 20(42):377-391.

PEREIRA, Pedro Paulo Gomes. 2010. "Violência, gênero e cotidiano: o trabalho de Veena Das". Cadernos Pagu, 35:357-369.

. 2014. De corpos e travessias: uma antropologia de corpos e afeto. São Paulo: Annablume.

RIORDAN, Brian. 2005. "Language policy for linguistic minority students in Japanese public schools and prospects for bilingualism: the Nikkei Brazilian case". IULC Working Papers, 5:1-33.

ROTH, Joshua H. 2002. Brokered homeland: Japanese Brazilian migrants in Japan. New York: Cornel University Press.

RYANG, Sonia. 2004. Japan and national anthropology: a critique. New York: Routledge Curzon. . 2005. Koreans in Japan: critical voices from the margin. New York: Routledge.

SASAKI, Elisa Massae. 2009. Ser ou não ser japonês? A construção da identidade dos brasileiros descendentes de japoneses no contexto das migrações internacionais do Japão contemporâneo. Tese de Doutorado em Ciências Sociais, Universidade Estadual de Campinas.

SEKIGUCHI, Sumiko. 2010. "Confucian morals and the making of a 'good wife and wise mother': from 'between husband and wife there is distinction' to as 'husbands and wives be harmonious'". Social Science Japan Journal, 13(1):95-113. 
SHISHITO, Anderson Akio \& SOUZA, José Gilberto. 2016. "Construção e contiguidade territorial em terras distantes: os Dekassegui". Geosul, 31(62):299-316.

SHUTO, Wakana. 2009. "Occupational sex segregation and the Japanese employment model: case studies of the railway and automobile industries". Japan Labor Review, 6(1):2135.

SILVA, Hélio R. 2015. "Entrevista com Luiz Eduardo Soares". Iluminuras, 16(38):315-345.

STOLLER, Paul. 1997. Fusion of the worlds: an ethnography of possession among the Songhay of Niger. Chicago: University of Chicago Press.

TSUDA, Takeyuki. 2006. Local citizenship in recent countries of immigration. New York: Lexington.

TURNER, Bryan S. 2011. Religion and modern society: citizenship, secularisation and the State. Cambridge:
WEINER, Myron (ed.). 2004. Japan's minorities: illusion of homogeneity. London: Routledge.

WEINER, Myron; HANAMI, Tadashi (eds.). 1998. Temporary workers or future citizens? Japanese and U.S. migration policy. New York: New York University Press.

YAMANAKA, Keiko. 2003. "I will go home, but when?: labor migration and circular diaspora formation by Japanese Brazilian in Japan". In: M. Douglas \& G. S. Roberts (eds.), Japan and global migration: foreign workers and the advent of a multicultural society. Honolulu: University of Hawai'i Press. pp. 123-152.

YAMASHITA, Shinji. 2004. "Selves and others in Japanese anthropology: the case of Micronesia e Southeast Asian studies". In: S. Yamashita, J. Bosco \& J. S. Eades (eds.), The making of anthropology in East and Southeast Asia. New York: Berghahn Books. 
"QUEM SE DIFERENCIA APANHA"

(DERU KUI HA WATARERU):

EXPERIÊNCIA ETNOGRÁFICA, AFETO

E ANTROPOLOGIA NO JAPÃO
“THE NAIL THATSTANDS UP GETS HIT DOWN" (DERU KUI HA WATARERU): ETHNOGRAPHICAL EXPERIENCE, AFFECT AND ANTHROPOLOGY IN JAPAN

\section{Resumo}

Com base em uma etnografia realizada no Japão por quase uma década, descrevemos neste artigo os afetos na experiência etnográfica. Nele narramos episódios em que se destacam as sensações de inadequação e incompletude, centrando a análise no corpo como algo que personifica a diferença. Posteriormente, discorreremos sobre o trabalho de campo elaborado pela primeira autora entre os brasileiros no Japão, evidenciando como estes se tornaram uma minoria marginalizada no país. Mostraremos a seguir como se deu historicamente - e como ainda se dá - a construção da alteridade na visão hegemônica do Estado e a existência de discursos e práticas que sustentam a "homogeneidade racial do povo japonês". Assinalaremos depois os efeitos desses discursos e dessas práticas sobre os corpos de seus interlocutores e sobre seu próprio corpo. Por fim, destacaremos elementos de uma "teoria vivida", que inclui demandas de ordem biográfica e dos afetos. Tal antropologia é também terapêutica, pois, além de estar aberta às teorias e às experiências vividas, possibilita também a inclusão dos saberes e do afeto não representado. Palavras-chave: Etnografia, Japão, Migrantes brasileiros, Afeto, Teoria vivida.

\begin{abstract}
Based on an ethnography carried on for almost a decade in Japan, we described affects in the ethnographic experience. At first, we narrate episodes that highlight the feeling of inadequacy and incompleteness, centering the analysis on how the body as a personification of difference. We then describe the field work carried out by the first author among Brazilians in Japan, emphasizing how this group became marginalized in this country. We also reveal how alterity was constructed, both historically and at present, showing how this concept is blurred by the dominant State discourse on the "racial homogeneity of the Japanese people". Moreover, we stress the effects of these discourses and practices on the ethnographer and on her interlocutor's bodies. In conclusion, we emphasise a "lived theory" in the field of anthropology, which incorporates biographical elements and affects. This kind of anthropological approach can be therapeutic, because it includes theories and lived experience, but also the unrepresented knowledge and affects.

Key words: Ethnography, Japan, Brazilian migrants, Affection, Lived theory.
\end{abstract}


“QUIEN SE DIFERENCIA, SUFRE”

(DERU KUI HA WATARERU):

EXPERIENCIA ETNOGRÁFICA,

AFECTO Y ANTROPOLOGÍA EN

JAPÓN

\section{Resumen}

Con base en una etnografía realizada en Japón durante casi una década, este artículo describirá los afectos en la experiencia etnográfica. Narramos episodios en los cuales se destacan las sensaciones de inadecuación y falta, centrando el análisis en el cuerpo como algo que personifica la diferencia. Posteriormente, nos centramos en el trabajo de campo elaborado por la primera autora entre los brasileños viviendo en Japón, evidenciando la manera en que ese grupo poblacional se convirtió en una minoría marginalizada en este país. Luego mostraremos como se dio históricamente - y como aún se da - la construcción de una alteridad en la visión hegemónica del Estado, así como la existencia de discursos y prácticas que sustentan la "homogeneidad racial del pueblo japonés". Posteriormente, señalaremos los efectos de esos discursos y de esas prácticas sobre los cuerpos de sus interlocutores y sobre su propio cuerpo. Finalmente, destacaremos elementos de una "teoría vivida", que incluye demandas de orden biográfica y de los afectos. Dicha antropología también es terapéutica, ya que, más allá de estar abierta a teorías y experiencias vividas, posibilita la inclusión de saberes y del afecto no representado.

Palabras clave: Etnografía, Japón, Migrantes brasileños, Afecto, Teoría vivida. 